MR Assessment of Myocardial Perfusion, Viability, and Function after Intramyocardial Transfer of VM202, a New Plasmid Human Hepatocyte Growth Factor in Ischemic Swine Myocardium ${ }^{1}$

Maythem Saeed, DVM, PhD

Alastair Martin, PhD

Phillip Ursell, MD

Loi Do, BS

Matt Bucknor, BA

Charles B. Higgins, MD

David Saloner, PhD
${ }^{1}$ From the Departments of Radiology and Biomedical Imaging (M.S., A.M., L.D., M.B., C.B.H., D.S.) and Pathology (P.U.), University of California San Francisco, 513 Parnassus Ave, HSW 207B, San Francisco, CA 941340628. Received September 5, 2007; revision requested November 20; revision received January 11, 2008; accepted February 26; final version accepted March 13. Supported by a grant (R01HL7295) from the National Institutes of Health (M.S.) and a gift from ViroMed, Seoul, South Korea. Address correspondence to M.S. (e-mail: Maythem.Saeed@radiology.UCSF.edu).
Purpose:

Materials and Methods:

Results:

Conclusion:
VM202, a newly constructed plasmid human hepatocyte growth factor, was transferred intramyocardially after infarction for the purpose of evaluating this strategy as a therapeutic approach for protection from left ventricular (LV) remodeling.

The institutional animal care and use committee approved this study. Pigs underwent coronary artery occlusion and reperfusion and served as either control $(n=8)$ or VM202-treated $(n=8)$ animals. VM202 was transferred intramyocardially into four infarcted and four periinfarcted sites. Cardiac magnetic resonance (MR) imaging (cine, perfusion, delayed enhancement) was performed in acute ( 3 days) and chronic (50 days \pm 3 [standard error of the mean]) infarction. Histopathologic findings were used to characterize and quantify neovascularization. The $t$ test was utilized to compare treated and control groups and to assess changes over time.

In acute infarction, MR imaging estimates of function, perfusion, and viability showed no difference between the groups. In chronic infarction, however, VM202 increased maximum signal intensity and upslope at first-pass perfusion imaging and reduced infarct size at perfusion and delayed-enhancement imaging. These changes were associated with a decrease in end-diastolic $(2.15 \mathrm{~mL} / \mathrm{kg} \pm 0.12$ to $1.73 \mathrm{~mL} / \mathrm{kg} \pm$ $0.10, P<.01)$ and end-systolic $(1.33 \mathrm{~mL} / \mathrm{kg} \pm 0.07$ to 0.92 $\mathrm{mL} / \mathrm{kg} \pm 0.08, P<.001)$ volumes and an increase in ejection fraction $(38.2 \% \pm 1.3$ to $47.0 \% \pm 1.8, P<.001)$. In contrast, LV function deteriorated further in control animals. Compared with control animals, VM202-treated animals revealed peninsulas and/or islands of viable myocardium in infarcted and periinfarcted regions and greater number of capillaries (218 per square millimeter \pm 19 vs 119 per square millimeter $\pm 17, P<.05)$ and arterioles (21 per square millimeter \pm 4 vs 3 per square millimeter $\pm 1, P<.001)$.

Intramyocardial transfer of VM202 improved myocardial perfusion, viability, and LV function.

( RSNA, 2008 
t has been postulated that progressive left ventricular (LV) dysfunction after myocardial infarction is because of the decrease in myocardial perfusion and scar formation $(1,2)$. Currently available approaches for treating ischemic cardiomyopathy aim to relieve symptoms and the risk of LV remodeling after infarction by reducing myocardial oxygen demand (by using drugs), reducing circulating vasoactive hormones (by using drugs), restoring coronary blood flow either with a pharmacologic method (thrombolysis) or a mechanical method (angioplasty), or bypassing the stenotic lesions and obstructed coronary artery segments (surgery). Local gene therapy is emerging as a potential new treatment for ischemic cardiomyopathy.

\section{Advances in Knowledge}

- Intramyocardial transfer of VM202, a new plasmid human hepatocyte growth factor (HGF), increases vascular density in infarcted $(83 \%, P<.05$ in capillaries and $708 \%, P<.001$ in arterioles) and periinfarcted $(69 \%$, $P<.05$ in capillaries and $458 \%$, $P<.01$ in arterioles) regions, thereby increasing myocardial perfusion.

- Intramyocardial transfer of VM202 activates the formation of peninsulas and/or islands of viable myocardium in scar tissue and improves infarct healing (16.5\% of left ventricular [LV] mass \pm 1.8 to $7.0 \%$ of $\mathrm{LV}$ mass \pm 0.5$)$ compared with that in control animals $(16.6 \%$ of $\mathrm{LV}$ mass \pm 1.1 to $13.2 \%$ of $\mathrm{LV}$ mass $\pm 1.6, P<.05)$.

- Intramyocardial transfer of VM202 prevents the increase in $\mathrm{LV}$ volume (decreased end-systolic volume from $1.33 \mathrm{~mL} / \mathrm{kg} \pm 0.07$ to 0.92 $\mathrm{mL} / \mathrm{kg} \pm 0.08, P<.001)$ associated with infarction (increase in end-systolic volume from $1.31 \mathrm{~mL} /$ $\mathrm{kg} \pm 0.03$ to $1.57 \mathrm{~mL} / \mathrm{kg} \pm 0.05$, $P<.05)$ and increases ejection fraction $(38.2 \% \pm 1.3$ to $47.0 \% \pm$ $1.8, P<.001)$.
The application of gene therapy for myocardial infarction requires intense preclinical assessment to determine the optimum gene, its effectiveness, and best route for delivery. Noninvasive monitoring of the effectiveness of gene therapy for cardiac infarction will serve these objectives. Thus, a variety of medical imaging modalities, such as positron emission tomography, single photon emission computed tomography, ventriculography, echocardiography, and optical imaging, have been concurrently used in the evaluation of angiogenic proteins, genes, and stem cells delivered into infarcted myocardium. Magnetic resonance (MR) imaging has been recently used after transfer of angiogenic genes $(3,4)$ and stem cells $(5,6)$.

Investigators $(7,8)$ found a cardiac hepatocyte growth factor (HGF) system that is upregulated after infarction and reperfusion. Furthermore, clinical studies have shown that the increase in HGF level is associated with decreased $\mathrm{LV}$ dilatation $(9,10)$ and improved $\mathrm{LV}$ function (8). Pharmacologic studies demonstrated that HGF is a potent angiogenic (11), antifibrotic (12), and antiapoptotic agent (11). Accordingly, a therapeutic approach that increases perfusion and decreases fibrosis after infarction is a feasible strategy to attenuate LV remodeling. VM202 is a gene-encoding human HGF and simultaneously expresses two isoforms of HGF, one consisting of 728 amino acids (known as HGF) and the other consisting of 723 amino acids (known as deleted HGF) (13). Although the newly developed plasmid human HGFs-HGF and deleted HGF - share several biologic functions, they are different in terms of immunologic and biologic properties and therapeutic efficacy $(14,15)$. In this MR imaging study,

\section{Implications for Patient Care}

- The newly constructed plasmid human HGF, VM202, may be useful for revascularization of ischemic myocardium.

a The MR protocol used in the current study can be applied in the evaluation of newly designed angiogenic therapies.
VM202 was transferred intramyocardially after infarction for the purpose of evaluating this strategy as a therapeutic approach for protection from LV remodeling.

\section{Materials and Methods}

\section{HGF Expression Construct VM202}

The therapeutic efficacy of plasmid human HGF VM202 (ViroMed, Seoul, South Korea) was tested after infarction. VM202 contains a genomic complementary DNA hybrid of human HGF gene, HGF-X7, which can express isoforms of $\mathrm{HGF}$ and deleted HGF through alternative splicing. For construction of VM202, HGF-X7 was inserted into a pyruvate cardoxykinase DNA vector (16). The components of VM202 and their function are shown in Table 1. Guerbet Group (Paris, France) provided gadoterate meglumine (Dotarem).

\section{Experimental Model}

The institutional animal care and use committee approved this investigation. The experimental work spanned the course of 2.5 years (ended on May 2007) as a part of a National Institutes of Health grant. Pigs $(n=20,30 \mathrm{~kg} \pm$ 4 [standard error of the mean]) were premedicated and anesthetized and underwent surgery as described previously (17) (M.S., with 20 years of

\section{Published online before print 10.1148/radiol.2483071579 \\ Radiology 2008; 249:107-118 \\ Abbreviations: \\ $\mathrm{HGF}=$ hepatocyte growth factor \\ $\mathrm{LV}=$ left ventricle \\ TTC $=$ triphenyltetrazolium chloride}

\section{Author contributions:}

Guarantor of integrity of entire study, M.S.; study concepts/study design or data acquisition or data analysis/ interpretation, all authors; manuscript drafting or manuscript revision for important intellectual content, all authors; manuscript final version approval, all authors; literature research, M.S.; experimental studies, M.S., A.M., P.U., L.D., M.B.; statistical analysis, M.S., L.D., M.B.; and manuscript editing, all authors

See also Science to Practice in this issue. 
experience). The left anterior descending coronary artery was occluded for 2 hours, followed by 1 hour of reperfusion. Four animals died during left anterior descending coronary occlusion or early reperfusion. Surviving animals $(n=16)$ were randomly divided into VM202-treated $(n=8)$ and control $(n=8)$ groups. VM202 (2 $\mathrm{mg})$ was dissolved in a saline solution and injected (30 seconds) directly into the periinfarcted and infarcted myocardium, as determined by discoloration and regional wall motion at the epicardial surface. Each heart received eight injections $(0.25 \mathrm{~mL}$ per site) (four at periinfarcted and four at infarcted myocardium) with a 27 - gauge needle (M.S., with 5 years of experience; M.B., with 1 year of experience) $(4,18)$. Control animals underwent precisely the same pathologic intervention (open chest surgery, coronary artery occlusion, and reperfusion) but did not receive HGF vehicle injection. Arterial blood pressures, $\mathrm{PO}_{2}, \mathrm{PCO}_{2}$, and heart rate were measured. Peripheral

\begin{tabular}{|c|c|c|}
\hline \multicolumn{3}{|c|}{ Main Components of VM202 and Their Location and Function } \\
\hline Gene & Location (base pair) & Function \\
\hline Human cytomegalovirus enhancer and promoter & $1-1568$ & $\begin{array}{l}\text { A promoter originated from the major immediate early gene of human cytomegalovirus } \\
\text { and drives the expression of HGF-X7; located downstream }\end{array}$ \\
\hline HGF-X7 & $1584-5262$ & $\begin{array}{l}\text { A genomic complementary DNA hybrid of human HGF, the expression of which is able } \\
\text { to induce formation of mature vessels by promoting growth of endothelial cells and } \\
\text { migration of smooth muscle cells of blood vessels }\end{array}$ \\
\hline Poly(adenylic acid) (bovine growth hormone) & $5300-5514$ & $\begin{array}{l}\text { The polyadenylation sequence of bovine growth hormone gene which is used to } \\
\text { terminate the transcription of the target gene (HGF-X7); located upstream }\end{array}$ \\
\hline Phosphotransferase (Kan') & $5523-6317$ & $\begin{array}{l}\text { A gene that confers resistance to the antibiotic kanamycin and is used for selective } \\
\text { culturing of Escherichia coli carrying the plasmid DNA }\end{array}$ \\
\hline Colicin E1 & $6703-7376$ & $\begin{array}{l}\text { The origin of replication for the plasmid DNA which controls replication of the plasmid } \\
\text { within } E \text { coli }\end{array}$ \\
\hline
\end{tabular}

\section{Figure 1}
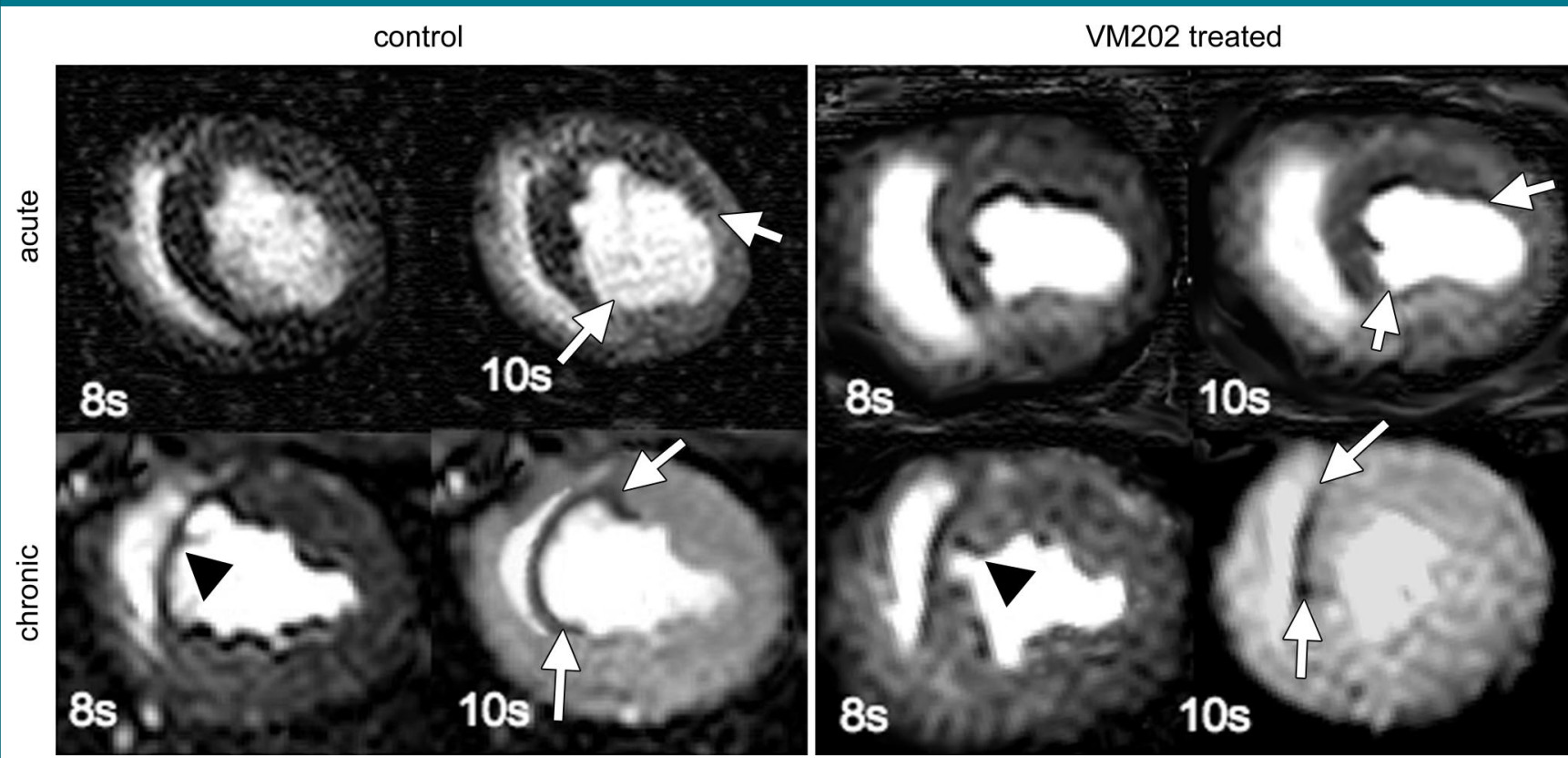

Figure 1: First-pass perfusion MR images show ischemic region as hypoenhanced (arrows) in both groups on early images. In acute infarction, the extent of hypoenhanced region was identical in control and treated animals; however, in chronic infarction, it was substantially smaller in VM202-treated animals than in control animals, suggesting better perfusion. Arrowheads show the thin chronically infarcted wall in a control animal and the relatively thick wall in a treated animal. $8 \mathrm{~s}=8 \mathrm{~seconds}$, $10 \mathrm{~s}=10$ seconds 
Figure 2
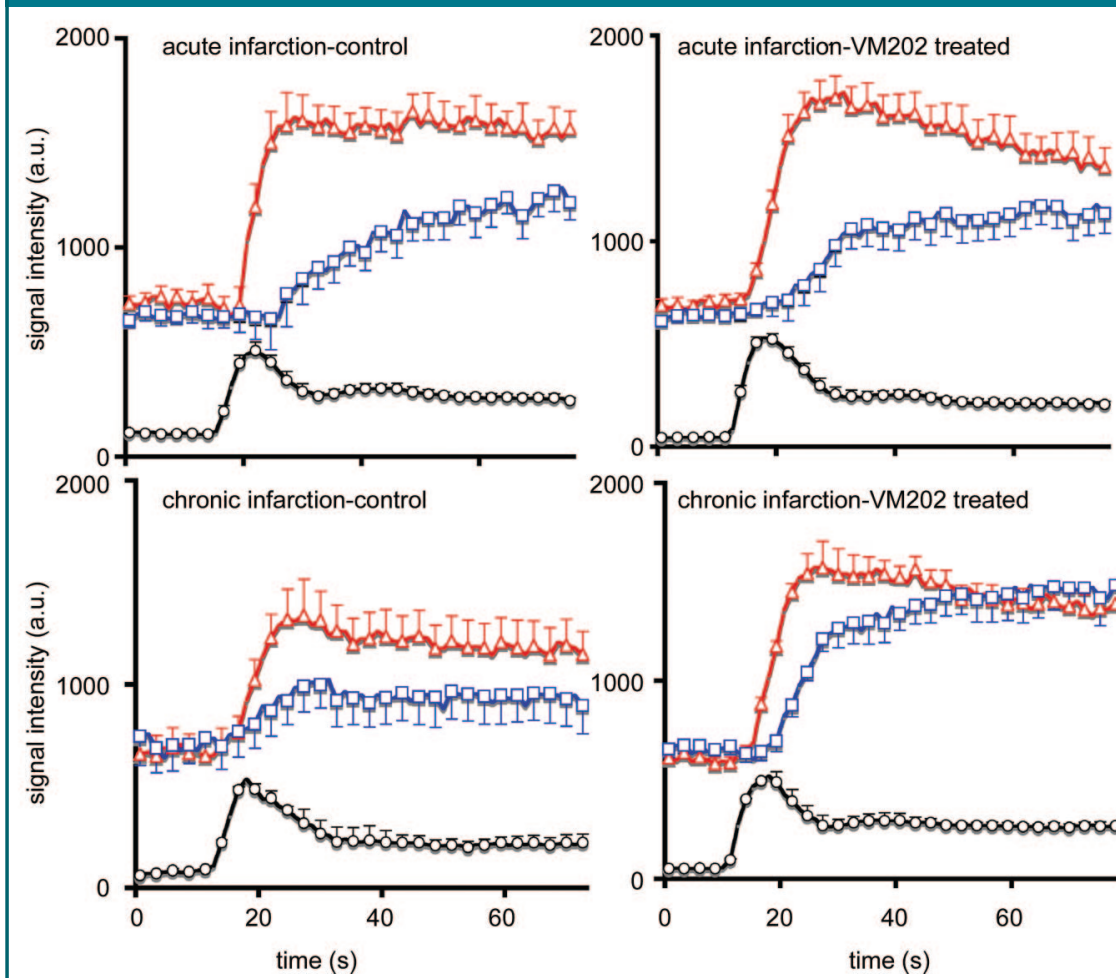

20007 chronic infarction-VM202 treated

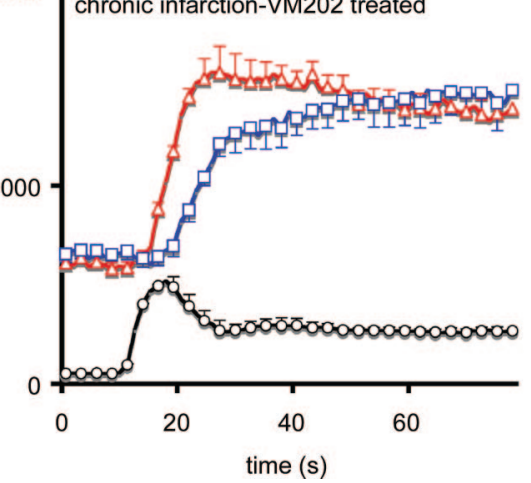

Figure 2: Plots of first-pass perfusion dynamics of MR contrast medium in LV blood (signal intensity was divided by 10 for clarity) (black line and circle), remote myocardium (red line and triangle), and ischemic myocardium (blue line and square) in control (left) and VM202-treated (right) animals after administration of $0.1 \mathrm{mmol} / \mathrm{kg}$ gadoterate meglumine. Chronically infarcted myocardium of VM202-treated animals showed better perfusion than in control animals. A rapid wash-in of gadoterate meglumine was also observed in treated compared with that of control animals. a.u. = arbitrary units.

\section{Table 2}

First-Pass MR Perfusion Measurements in Control and VM202-Treated Animals in Acute and Chronic Infarction

\begin{tabular}{|c|c|c|c|c|c|}
\hline \multirow[b]{2}{*}{ Parameter } & \multicolumn{2}{|c|}{ Acute Infarction } & \multicolumn{2}{|c|}{ Chronic Infarction } & \multirow[b]{2}{*}{$P$ Value $^{*}$} \\
\hline & $\begin{array}{l}\text { Control } \\
\text { Animals }\end{array}$ & $\begin{array}{l}\text { Treated } \\
\text { Animals }\end{array}$ & $\begin{array}{l}\text { Control } \\
\text { Animals }\end{array}$ & $\begin{array}{l}\text { Treated } \\
\text { Animals }\end{array}$ & \\
\hline \multicolumn{6}{|l|}{ Remote myocardium } \\
\hline Maximum upslope $\left(\mathrm{sec}^{-1}\right)$ & $205 \pm 31$ & $198 \pm 18$ & $249 \pm 24$ & $204 \pm 24$ & .21 \\
\hline Peak signal intensity (au) & $1550 \pm 90$ & $1700 \pm 67$ & $1198 \pm 124$ & $1538 \pm 127$ & .04 \\
\hline \multicolumn{6}{|l|}{ Ischemic myocardium } \\
\hline \multicolumn{6}{|l|}{$\begin{array}{l}\text { Extent of hypoenhanced } \\
\text { ischemic myocardium } \\
\text { (percentage of LV }\end{array}$} \\
\hline mass) & $41.2 \pm 2.3$ & $41.4 \pm 3.4$ & $32.8 \pm 2.0^{\dagger}$ & $17.4 \pm 3.0^{\dagger}$ & .001 \\
\hline Maximum upslope $\left(\mathrm{sec}^{-1}\right)$ & $188 \pm 38$ & $207 \pm 44$ & $225 \pm 19$ & $314 \pm 26^{\dagger}$ & .002 \\
\hline Peak signal intensity (au) & $1002 \pm 217$ & $980 \pm 66$ & $933 \pm 134$ & $1263 \pm 99$ & .001 \\
\hline
\end{tabular}

Note.-Unless otherwise indicated, data are means \pm standard errors of the mean. au $=$ Arbitrary units.

* $P$ values compare treated to control animals in chronic infarction. There was no significant difference between groups in acute infarction.

${ }^{\dagger} P$ value was less than .05 compared with acute infarction. vascular resistance was estimated from mean arterial pressure divided by cardiac output.

\section{MR Imaging}

Cardiac MR imaging was performed in acute (3 days) and chronic (50 days \pm 3 ) infarction by using a 1.5-T MR clinical imager (Philips Medical Systems, Best, the Netherlands) (A.M., with 15 years of experience). Retrospectively electrocardiographically gated images were acquired by using the following protocols:

Cine MR imaging. - A breath-hold cine balanced steady-state free precession sequence provided image loops of 16 cardiac phases. Acquired images showed the heart in contiguous shortaxis view and were used to measure LV chamber volumes and mass. The sequence parameters were as follows: repetition time msec/echo time msec, 4/2; section thickness, $10 \mathrm{~mm}$; spacing, 0 ; flip angle, $70^{\circ}$; field of view, $25 \times 25$ $\mathrm{cm}$; matrix size, $160 \times 152$; number of signals acquired, one; and phases, 16 $(4,17)$.

First-pass contrast material enhancement.-A saturation-recovery first-pass perfusion gradient-echo sequence was used for assessment of regional perfusion. Imaging parameters were as follows: $4.5 / 2.2$; section thickness, $3 \mathrm{~mm}$; field of view, $26 \times 26 \mathrm{~cm}$; matrix size, $128 \times 128$; flip angle, $20^{\circ}$; and acquisition time, $220 \mathrm{msec}$. A power injector (Spectris MRI Injector; Medrad, Indianola, $\mathrm{Pa}$ ) was used to deliver gadoterate meglumine $(0.1 \mathrm{mmol}$ per kilogram of body weight) and $20 \mathrm{~mL}$ saline solution at a rate of $3 \mathrm{~mL} / \mathrm{sec}$. Regional signal intensity changes as a function of time were plotted as shown previously by using software (Viewforum; Philips Medical Systems) and presented in arbitrary units (au) (19). Maximum signal intensity and upslope were used as parameters of perfusion (4).

Delayed contrast enhancement.Delayed contrast material-enhanced inversion-recovery gradient-echo shortaxis images were acquired at $20 \mathrm{~min}$ utes to define infarcted myocardium after an additional dose of $0.05 \mathrm{mmol} / \mathrm{kg}$ gadoterate meglumine $(20,21)$. Imaging 


\section{Figure 3}
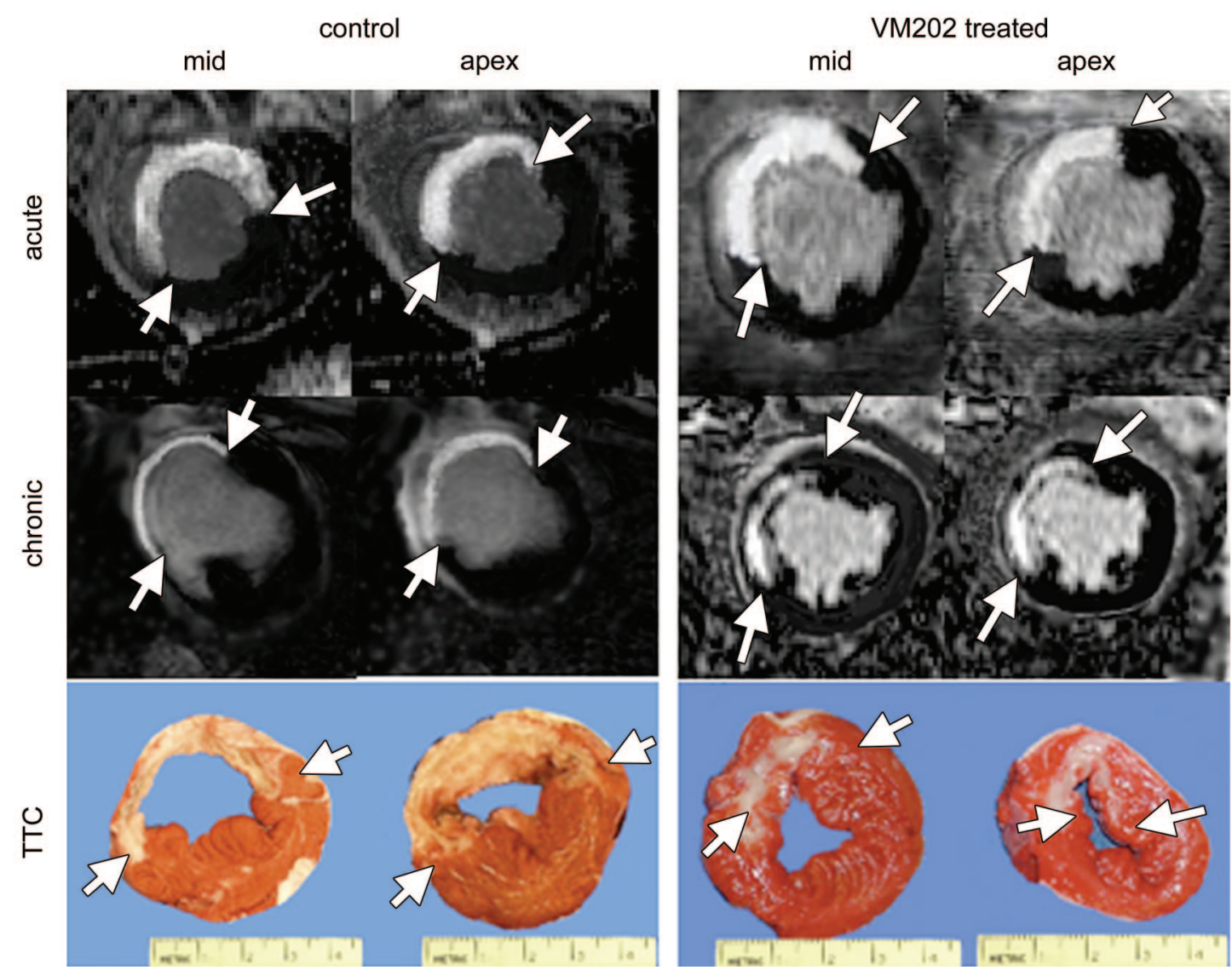

Figure 3: Delayed contrast-enhanced MR images show the differentially enhanced acute infarcted myocardium and scar tissue as bright regions in control and treated animals (arrows), with corresponding gross specimens (bottom) showing the extent of myocardial infarction (arrows). Note the change in the extent of differentially enhanced infarction in control and VM202-treated animals. In VM202-treated animals, the ischemic wall was thicker and the infarction was nontransmural compared with control animals at both MR imaging and TTC staining.

parameters were as follows: 5.2/1.5; section thickness, $3 \mathrm{~mm}$; number of sections, 20; spacing, 0; flip angle, $15^{\circ}$; field of view, $26 \times 26 \mathrm{~cm}$; number of signals acquired, one for three-dimensional volume; and matrix size, $256 \times$ 162. The inversion time was between 270 and 325 msec. MR images and triphenyltetrazolium chloride (TTC)-stained slices were visually matched on the basis of anatomic landmarks (17).

\section{Image Analysis}

Morphometric LV parameters (surface area and mass) were measured by tracing the circumferential borders of endocardium and epicardium of each section during systole and diastole by using software (Viewforum) $(4,17,22)$. Analyses of the images were performed by consensus (M.S., with experience of 20 years; A.M., 15 years; L.D., 3 years; M.B., 1 year). LV mass (in grams) and volumes (in milliliters) to body weight (in kilograms) ratios were used to demonstrate the changes in LV mass and volumes due to the change in body weight of the animals (30 kg \pm 4 at 3 days to $49 \mathrm{~kg} \pm 5$ at 50 days \pm 3 ).

Perfusion images were inverted to delineate the hypoenhanced region as a hyperenhanced region (percentage of three sections of surface area). On the inverted first-pass images, the ischemic region was identified as a region with signal intensity greater than 2.0 standard deviations above the mean signal intensity on three images in remote myocardium by using software (ImageJ; National Institutes of Health, Bethesda, Md). Myocardial infarction was visualized on delayed contrast-enhanced MR images $(13,14)$ and measured in the same fashion as the hyperenhanced ischemic region without inverting the image signal intensity.

For measuring infarct transmurality (percentage of LV wall thickness) in the anteroseptal wall in control and treated animals, the same three sections used for perfusion measurements were used. Infarct transmurality was determined in eight segments of each section by using the centerline method. Mean data from the three sections were expressed as a percentage of total wall thickness in all segments by using freely available soft- 
Figure 4

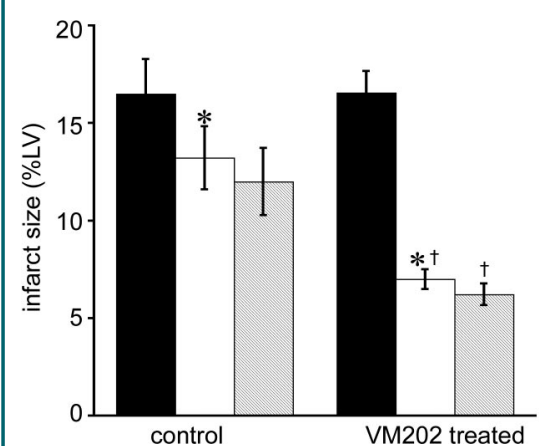

Figure 4: Histogram shows the difference in acute (black columns) and chronic (white columns) infarctions in control $(n=8)$ and VM202treated animals $(n=8)$ measured at MR imaging and TTC staining. Both groups demonstrated decline in size of infarction because of infarct healing, but the decline was greater in VM202-treated than in control animals. MR imaging and TTC staining (striped columns) measurements of chronic infarctions were not significantly different. $*=P<.05$ compared with acute infarction. $\dagger=$ $P<.05$ compared with chronic infarction in control animals. $\% L V=$ percentage of $L V$ mass. Error bars $=$ standard error of the mean ware (Segment, version 1.663; http: //segment.heiberg.se) (M.S. and L.D., each with 1 year of experience) (23).

\section{Postmortem Evaluation}

At the conclusion of the last imaging session, the LV was dissected, weighed, sliced, and stained with TTC to discriminate scar tissue (white) from viable myocardium (red brick). True infarction size on TTC-stained slices was measured (percentage of LV mass) by using software (ImageJ) (M.S., with 20 years of experience; L.D., 3 years; and M.B., 1 year). The slices of the LV were then fixed in $10 \%$ buffered formalin. Transmural tissue samples were obtained from remote periinfarcted myocardium and scar tissue and embedded in paraffin. Thin slices (5 $\mu \mathrm{m})$ were stained with hematoxylineosin, Masson trichrome, and biotinylated Bandeiria simplicifolia isolectin B4 (24). Capillary $(<15 \mu)$ and arteriole $(>15$ to $100 \mu)$ densities (capillaries or vessels per square millimeter) were measured by three investigators (P.U., with

\section{Table 3}

Hemodynamic Measurements in Acute and Chronic Infarction in Swine

\begin{tabular}{lccccc} 
& \multicolumn{2}{c}{ Acute Infarction } & & \multicolumn{2}{c}{ Chronic Infarction } \\
\cline { 2 - 3 } Parameter & $\begin{array}{l}\text { Control } \\
\text { Animals }\end{array}$ & $\begin{array}{l}\text { Treated } \\
\text { Animals }\end{array}$ & & $\begin{array}{l}\text { Control } \\
\text { Animals }\end{array}$ & $\begin{array}{l}\text { Treated } \\
\text { Animals }\end{array}$ \\
\hline Heart rate (beats/min) & $90 \pm 3$ & $93 \pm 6$ & & $91 \pm 3$ & $92 \pm 5$ \\
Mean blood pressure $(\mathrm{mm} \mathrm{Hg})$ & $74 \pm 2$ & $76 \pm 4$ & & $77 \pm 4$ & $75 \pm 8$ \\
Diastolic blood pressure $(\mathrm{mm} \mathrm{Hg})$ & $61 \pm 2$ & $58 \pm 5$ & & $61 \pm 4$ & $56 \pm 7$ \\
Systolic blood pressure $(\mathrm{mm} \mathrm{Hg})$ & $99 \pm 3$ & $102 \pm 3$ & & $97 \pm 4$ & $100 \pm 9$ \\
$\begin{array}{l}\text { Peripheral resistance }(\mathrm{mm} \mathrm{Hg} / \\
\quad \mathrm{mL} / \mathrm{min} / \mathrm{kg})\end{array}$ & $0.87 \pm 0.04$ & $0.97 \pm 0.1$ & & $1.03 \pm 0.06$ & $1.05 \pm 0.10$ \\
Arterial $\mathrm{O}_{2}$ saturation $(\%)$ & $97 \pm 2$ & $98 \pm 2$ & & $98 \pm 2$ & $98 \pm 2$ \\
MR imaging of LV mass $(\mathrm{g} / \mathrm{kg})$ & $2.6 \pm 0.1$ & $2.5 \pm 0.1$ & $2.3 \pm 0.1$ & $2.4 \pm 0.1$ \\
\hline
\end{tabular}

Note.-Data are means \pm standard errors of the mean. There were no significant differences.

\section{Figure 5}
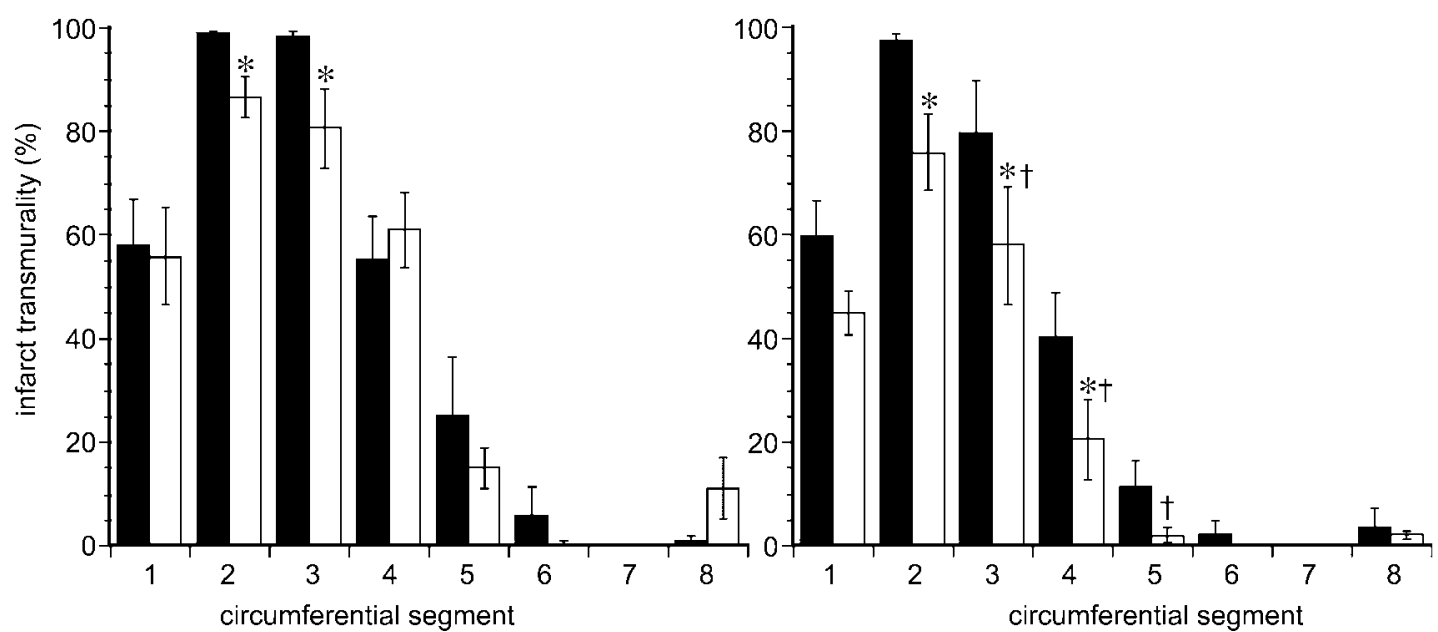

Figure 5: Graphs of quantitative analysis of infarct transmurality in eight circumferential segments in acute (left) and chronic (right) infarctions in control (black columns) and VM202-treated (white columns) animals. Average infarct transmurality was obtained from the same three perfusion sections. Note the significant decline in infarct transmurality of the anteroseptal wall of treated animals. $*$ and $\dagger=P<.05$ compared with acute infarction within the group and chronic infarctions between the groups, respectively. Error bars $=$ standard error of the mean . 


\section{Figure 6}
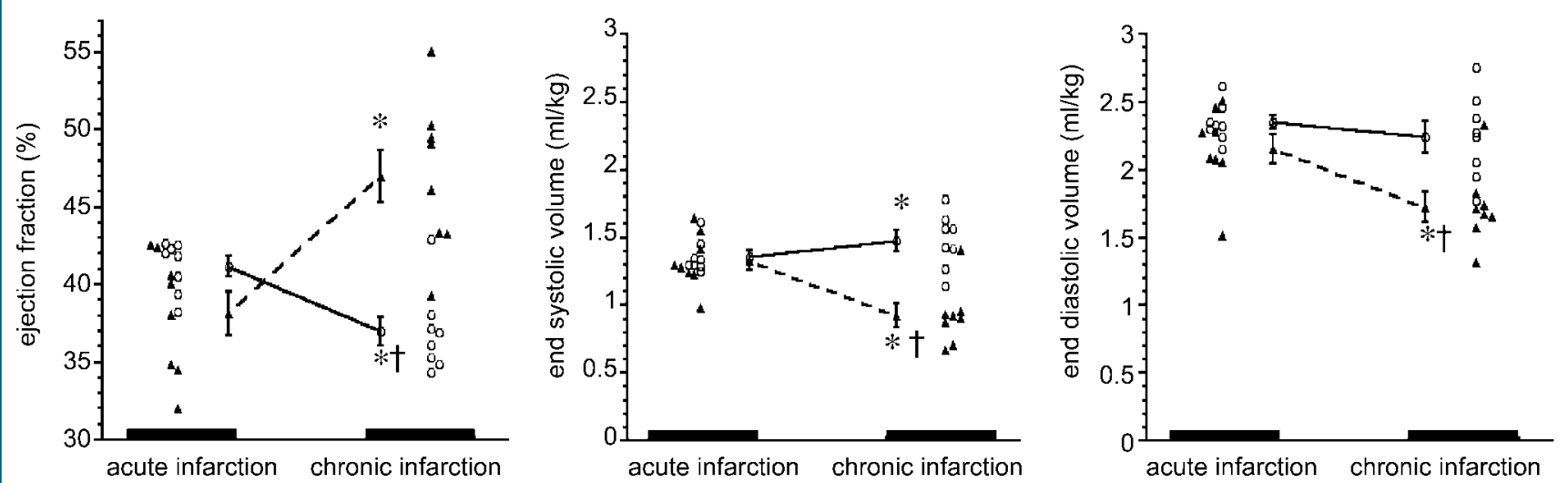

Figure 6: Graphs of ejection fraction (left), end-systolic volumes (center), and end-diastolic volumes (right) for control (circles) and VM202-treated (triangles) groups. VM202 gene therapy significantly decreased end-diastolic and end-systolic volumes at chronic infarction compared with acute infarction and control group. Control animals with chronic infarction showed progressive decline in ejection fraction and significant increase in both end-systolic and end-diastolic volumes compared with acute infarction ( $*$ and + : refer to text for specific $P$ values)

25 years of experience; M.S., 25 years; L.D., 3 years) who were not blinded to treatment in 12 fields of each animal, namely, four in remote area, four in periinfarcted myocardium, and four in scar tissue at $\times 400$ magnification (4). Arteriole wall thickness and lumen diameter were measured in both groups by using calibrated reticule ocular lenses.

\section{Statistical Analysis}

Changes over time were compared by using the two-tailed $t$ test for repeated measurements to determine significant group differences. When a significant result was observed, the Tukey test was conducted to determine which groups were significantly different from one another. The extents of hypoenhanced ischemic myocardium, contrast-enhanced infarction, infarct transmurality, LV volume, LV ejection fraction, maximum signal intensity, maximum upslope, vascular density, arteriole wall thickness, and lumen diameter were compared. $P$ less than .05 was considered to indicate a statistically significant difference (M.S., with 20 years of experience; L.D., 5 years; and M.B., 1 year).

\section{Results}

\section{Myocardial Perfusion}

In both groups, ischemic myocardium appeared as a hypoenhanced region with lower signal intensity than remote myocardium at first-pass perfusion MR imaging (Fig 1). During the first pass of MR contrast medium, the peak signal intensity and maximum upslope of remote myocardium were not significantly different between the groups in acute and chronic infarction (Fig 2, Table 2). The extent of ischemic myocardium was not significantly different between the groups at 3 days. In chronic infarction, maximum signal intensity and upslope were significantly higher and steeper and the extent of ischemic myocardium was smaller in VM202-treated animals than in control animals (Fig 2, Table 2).

\section{Contrast-enhanced Infarcted Myocardium}

Delayed contrast-enhanced MR images demonstrated anteroseptal infarction in pigs as a differentially enhanced region (Fig 3). The extent of acute infarction of myocardium was comparable between treated and control animals $(16.5 \%$ of LV mass \pm 1.8 vs $16.6 \%$ of $\mathrm{LV}$ mass \pm $1.1, P=.97)$. The MR enhanced region was significantly smaller in chronic than in acute infarction in both groups $(P<$ $.05)$ because of infarct healing (Fig 4). However, VM202-treated animals showed significantly smaller infarction at both MR imaging $(7.0 \%$ of $\mathrm{LV}$ mass \pm 0.5 , $P<.05)$ and TTC staining $(6.6 \%$ of $\mathrm{LV}$ mass $\pm 0.7, P<.05)$ than control animals $(13.2 \%$ of $\mathrm{LV}$ mass \pm 1.6 and
$12.0 \%$ of $\mathrm{LV}$ mass \pm 1.7 , respectively). There was no significant difference in the extent of scar tissue between that at MR imaging and that at TTC staining $(P=.32)$. Quantitative analysis showed decreased infarct transmurality in both groups. Infarct transmurality was not significantly different in acute infarction; however, chronic infarctions had less transmurality in treated than in control animals. The largest decrease in transmurality was restricted to the site of injections of VM202 (anterior LV wall; segments 3, 4, 5) (Fig 5). LV massto-body weight ratios (in grams per kilograms) showed no significant differences between control and VM202treated animals (Table 3 ).

\section{Function}

Cine MR imaging was used to determine whether the observed improvement in perfusion and reduction in the extent of hypoenhanced ischemic myocardium and scar tissue resulted in functional improvement. In acute infarction, there was no significant difference between groups with regard to end-diastolic volume $(2.35 \mathrm{~mL} / \mathrm{kg} \pm$ 0.04 for control group and $2.15 \mathrm{~mL} /$ $\mathrm{kg} \pm 0.10$ for treated group, $P=.13$ ) or end-systolic volume $(1.36 \mathrm{~mL} / \mathrm{kg} \pm$ 0.04 for control group and $1.33 \mathrm{~mL} /$ $\mathrm{kg} \pm 0.07$ for treated group, $P=.07$ ) (Fig 6). Control animals showed pro- 
gressive increase in end-systolic volume $(1.36 \mathrm{~mL} / \mathrm{kg} \pm 0.04$ to $1.51 \mathrm{~mL} /$ $\mathrm{kg} \pm 0.05, P<.05)$ and a significant decrease in ejection fraction $(41.2 \% \pm$ 0.8 to $36.9 \% \pm 0.9, P<.05)$ after infarction (Fig 6). On the contrary, VM202-treated animals showed improvement in $\mathrm{LV}$ function, as reflected by the decreased end-diastolic volume $(2.15 \mathrm{~mL} / \mathrm{kg} \pm 0.12$ to $1.73 \mathrm{~mL} / \mathrm{kg} \pm$ $0.10, P<.01)$ and end-systolic volume $(1.33 \mathrm{~mL} / \mathrm{kg} \pm 0.07$ to $0.92 \mathrm{~mL} / \mathrm{kg} \pm$ $0.08, P<.001)$ and increased ejection fraction $(38.2 \% \pm 1.3$ to $47.0 \% \pm 1.8$, $P<.001)$. There was no significant difference in heart rate, mean blood pressure, diastolic and systolic blood pressure, peripheral vascular resistance, and arterial $\mathrm{O}_{2}$ saturation between the two groups (Table 3 ).

\section{Histopathologic Studies}

Hematoxylin-eosin-stained slices were used for preliminary evaluation of viable myocardium and scar. Healed infarcts were composed of scar and adjacent viable myocardium (Fig 7). The periinfarcted and core regions showed sparse thin-walled vessels and scattered thickwalled vessels. The abundant thinwalled vessels in treated animals were in sharp contrast to thick-walled vessels that were dominant in control animals (Fig 8).
Quantitative analysis of capillary $(<15 \mu \mathrm{m})$ density in control animals revealed significant differences between remote myocardium, perïnfarcted myocardium $(P<.001)$, and scar tissue $(P<$ $.001)$. The density of the arterioles $(>15 \mu \mathrm{m})$, however, was not significantly different $(P=.44)$ between remote and periinfarcted myocardium but was significantly less in scar tissue compared with periinfarcted $(P<.05)$ and remote $(P<.01)$ myocardium.

Intramyocardial transfer of VM202 increased vascular density in infarcted (83\%, $P<.05$ in capillaries and $708 \%$, $P<.001$ in arterioles) and periinfarcted (69\%, $P<.05$ in capillaries and $458 \%$,

\section{Figure 7}

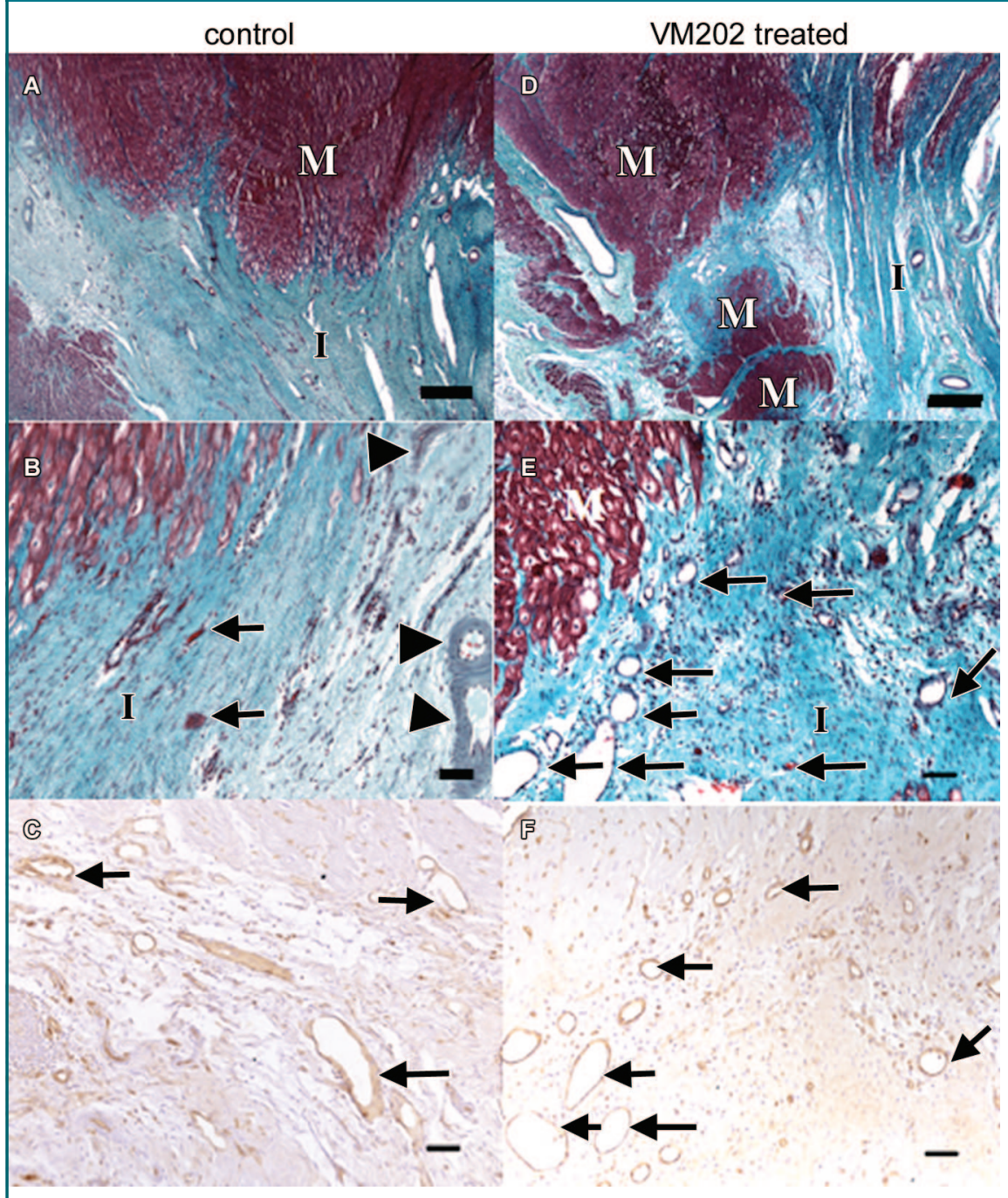

Figure 7: Light microscopic photographs of transverse slices of control and VM202-treated hearts. A, At low magnification, there is a sharp boundary between the scar of the healed infarct $(I)$ and viable myocytes $(M)$ in control heart 7-8 weeks after coronary artery occlusion and reperfusion. $B$, At the edge of the same infarction at higher magnification, few sparse thin-walled vessels (arrows) and thick-walled vessels (arrowheads) are present, as well as degenerated myocytes. $C$, Blood vessels (arrows) in periinfarcted myocardium are localized with brown reaction product of lectin stain. $D$, In contrast, a treated heart at low magnification shows irregular healed infarct (I) borders with several peninsulas and/or islands of viable myocytes (M) within it. E, At high magnification, the edge of the scar contains numerous thin-walled blood vessels (arrows in Eand $F$ ). Calibration bars in $A$ and $D=150 \mu \mathrm{m}$. Calibration bars in $B, C, E$, and $F=45 \mu \mathrm{m}$. ( $A, B, D$, and $E$, Masson trichrome stain; $C$ and $F$, biotinylated isolectin B4 stain.) 


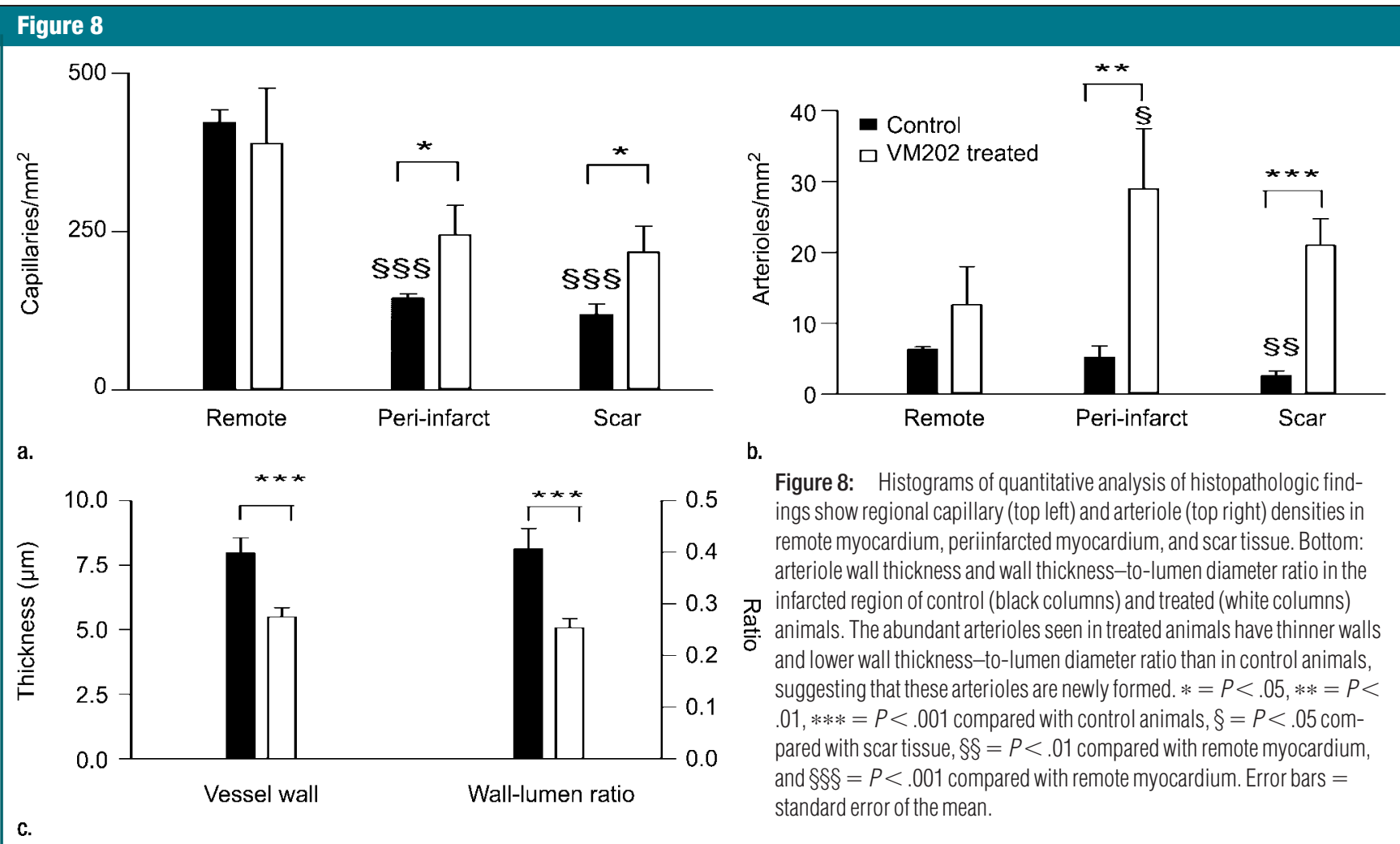

$P<.01$ in arterioles) regions, thereby increasing myocardial perfusion. Control animals showed tethering borders separating viable myocardium from scar. In contradistinction, treated animals showed collagen interdigitation with viable myocardium (peninsulas and/or islands) in the periinfarcted region and scar tissue (Fig 7). There was no significant difference in capillary density of normal remote myocardium between the groups $(P=.65)$. The capillary density in periinfarcted myocardium and scar tissue of treated animals was significantly greater than in control animals ( $P<.05$ for both regions). There was no significant difference in density of the arterioles $(>15 \mu \mathrm{m})$ in remote myocardium between the groups $(P=$ .17), but there was a significant difference in periinfarcted myocardium $(P<$ $.01)$ and scar tissue $(P<.001)$ between the groups (Fig 8).

\section{Discussion}

The current MR study is the first, to our knowledge, that demonstrates the ben- efits of VM202, a plasmid human HGF, on myocardial perfusion, vascular density, infarct healing, viability, and LV remodeling after infarction. The increase in regional perfusion and the decrease in the extent of hypoenhanced ischemic myocardium and scar tissue in treated animals are most likely related to the increase in neovascularization and the formation of peninsulas and/or islands of viable myocytes in infarcted and periinfarcted regions. Paracrine mechanism induced by HGF can be considered additional mechanism of protection against myocyte death (apoptosis) in periinfarcted myocardium $(25,26)$.

LV dysfunction in ischemic cardiomyopathy has been postulated to be due to a decrease in myocardial perfusion and scar formation $(27,28)$. The choice of proper angiogenic genes for ischemic cardiomyopathy and proper delivery strategy are currently topics of intense research $(11,29-34)$. With regard to the first aspect, we used the genomic complementary DNA hybrid of a HGF gene, which was designed to express two isoforms of HGF protein in an efficient manner. The in vivo expression of HGF proteins from the genomic complementary DNA hybrid construct VM202 has been confirmed by using the enzyme-linked immunosorbent assay method (30). With regard to the second aspect, the intramyocardial transfer strategy used in this study aims to (a) achieve a relatively high local concentration of therapy and maximize therapeutic outcome, (b) minimize the side effects or toxicity to remote organs, (c) reduce the systemic dose and cost of preparation of genes, and (d) eliminate the effect of blood enzymes on the therapeutic agent (33). Targeting of the periinfarction and infarction can be accomplished by using invasive (minithoracotomy) or minimally invasive (catheterbased) methods (18). The intramyocardial transfer strategy used in this study resembles that performed at the time of intervention at acute infarction in patients undergoing open chest surgery $(29,34,35)$. The current study involved intramyocardial injection into accessible regions (anterior LV wall and septal 
groove) within open chest surgical control (4). After confirmation of the beneficial effects of VM202 in this open chest animal model, it may be possible to use a guided catheter-based approach (32) to deliver the gene in future studies.

MR imaging was used in this study to monitor the effects of gene therapy because of its excellent spatial resolution, which allows determination of infarct transmurality and the true extent of acute and chronic infarction. Acute and chronic infarction of hearts showed differentially enhanced anteroseptal regions on delayed contrast-enhanced MR images. Both groups showed natural change (resorption) in infarct size during the course of the study. Our histopathologic findings are supported by previous study results that showed the enhanced healing process is accompanied by increased endogenous angiogenic growth factor production (36) and vascular density (4).

The VM202 gene caused significant reduction in infarct size and transmurality compared with that in control animals. The effect was more pronounced in the anterior wall and was most likely related to faster degradation of extracellular matrix (37) and inhibition of transforming growth factor- $\beta$ expression (38). Furthermore, the infarction tended to be partially repaired because of the antifibrotic effect of VM202 $(12,39,40)$ and the formation of viable peninsulas and/or islands. MR imaging and TTC staining results showed nontransmural thick infarcted walls in treated animals.

Of particular interest in this study was the viable myocardial peninsulas and/or islands at the periinfarcted and infarcted regions observed in treated animals. This favorable effect may be related to protection of surviving myocytes in the ischemic region by the antiapoptotic effect of HGF $(11,41)$. Published data $(27,42)$ suggest that the injection of a combination of HGF and insulin-like growth factor-1 into infarcted myocardium activates the production of endogenous cardiac stem cells. These cells have the capability to proliferate, differentiate, and eventually lead to substantial reconstitution of the necrotic myocardium. Furthermore, neovascularization in periinfarcted and infarcted regions induced by VM202 may salvage the myocytes that would otherwise be scarred or hibernating due to ischemia and stress, as shown in previous studies involving HGF genes $(27,42)$, and could potentially prevent recurrent episodes of demand-induced ischemia (43).

MR imaging is highly sensitive for the assessment of LV function after infarction (44-46) and therapy (44,4749). Both LV ejection fraction and endsystolic volume have been established as powerful predictors of short- and long-term morbidity and mortality in both pre- and postthrombolytic eras $(49,50)$. Furthermore, investigators (17, $51,52)$ have found that $\mathrm{LV}$ ejection fraction and end-systolic volume deteriorated after infarction, leading to structural (LV dilatation) and functional changes. Use of VM202 improved ejection fraction and reduced $\mathrm{LV}$ volumes. The improvement in LV function seen in this MR study confirms results of previous gene studies $(11,39)$ and was not related to difference in heart rate, blood pressure, or vascular resistance.

A major limitation of this study was that VM202 was not injected in the infarcted septum because of lack of access in this open chest model. This may explain why there was no significant difference in infarcted septum between the groups (Fig 5). HGF gene expression or the effect of a HGF vehicle was determined in a previous study (39). Azuma et al (39) found that an intramyocardial HGF vehicle has no effect on myocardial function. However, it should be noted that our experiment did not include a control injection of an HGF vehicle.

In conclusion, intramyocardial transfer of VM202 improved perfusion, viability, and function in infarcted myocardium. Our MR study is the first, to our knowledge, to demonstrate the biologic benefit of VM202. The mechanism of improvement of $\mathrm{LV}$ function lies in new blood vessels and viable myocardial peninsula and/or island formation in ischemic myocardium.
Practical application: Intramyocardial transfer of VM202 may be useful in revascularization of ischemic myocardium. A minimally invasive delivery procedure, catheter-based delivery, could enhance the application of gene therapy in patients with extensive coronary heart disease, heart failure, or refractory angina, for whom there are no other therapeutic options.

\section{References}

1. Beltrami CA, Finato N, Rocco $M$, et al. Structural basis of end-stage failure in ischemic cardiomyopathy in humans. Circulation 1994;89:151-163.

2. Parodi O, De Maria R, Oltrona L, et al. Myocardial blood flow distribution in patients with ischemic heart disease or dilated cardiomyopathy undergoing heart transplantation. Circulation 1993;88:509-522.

3. Pearlman JD, Laham RJ, Simons M. Coronary angiogenesis: detection in vivo with MR imaging sensitive to collateral neocirculation-preliminary study in pigs. Radiology 2000;214:801-807.

4. Saeed M, Saloner D, Martin A, et al. Adenoassociated viral vector-encoding vascular endothelial growth factor gene: effect on cardiovascular MR perfusion and infarct resorption measurements in swine. Radiology 2007;243:451-460.

5. Dick AJ, Guttman MA, Raman VK, et al Magnetic resonance fluoroscopy allows targeted delivery of mesenchymal stem cells to infarct borders in swine. Circulation 2003; 108:2899-2904.

6. Kraitchman DL, Tatsumi M, Gilson WD, et al. Dynamic imaging of allogeneic mesenchymal stem cells trafficking to myocardial infarction. Circulation 2005;112:1451-1461.

7. Ono K, Matsumori A, Shioi T, Furukawa Y, Sasayama S. Enhanced expression of hepato cyte growth factor/c-Met by myocardial ischemia and reperfusion in a rat model. Circula tion 1997;95:2552-2558.

8. Yasuda S, Goto Y, Baba T, et al. Enhanced secretion of cardiac hepatocyte growth fac tor from an infarct region is associated with less severe ventricular enlargement and improved cardiac function. J Am Coll Cardiol 2000;36:115-121.

9. Watanabe K, Fukuda H, Sueda S, Funada J, Kitakaze M, Sekiya M. Metabolism of hepatocyte growth factor in the heart in patients with coronary artery disease: implication for coronary arteriosclerosis. Cardiovasc Drugs Ther 2001;15:147-153. 
10. Soeki T, Tamura Y, Shinohara H, Tanaka H, Bando K, Fukuda N. Role of circulating vascular endothelial growth factor and hepatocyte growth factor in patients with coronary artery disease. Heart Vessels 2000;15:105111

11. Morishita R, Aoki M, Hashiya N, et al. Therapeutic angiogenesis using hepatocyte growth factor (HGF). Curr Gene Ther 2004; 4:199-206.

12. Taniyama $\mathrm{Y}$, Morishita R, Aoki M, et al. Angiogenesis and antifibrotic action by hepatocyte growth factor in cardiomyopathy. Hypertension 2002;40:47-53.

13. Seki T, Hagiya M, Shimonishi M, Nakamura $\mathrm{T}$, Shimizu S. Organization of the human hepatocyte growth factor-encoding gene. Gene 1991;102:213-219.

14. Bell A, Chen Q, DeFrances MC, Michalopoulos GK, Zarnegar R. The five amino acid-deleted isoform of hepatocyte growth factor promotes carcinogenesis in transgenic mice. Oncogene 1999;18:887-895

15. Shima N, Tsuda E, Goto M, et al. Hepatocyte growth factor and its variant with a deletion of five amino acids are distinguishable in their biological activity and tertiary structure. Biochem Biophys Res Commun 1994; 200:808-815.

16. Lee Y, Park EJ, Yu SS, Kim DK, Kim S. Improved expression of vascular endothelial growth factor by naked DNA in mouse skeletal muscles: implication for gene therapy of ischemic diseases. Biochem Biophys Res Commun 2000;272:230-235.

17. Saeed M, Lee RJ, Weber O, et al. Scarred myocardium imposes additional burden on remote viable myocardium despite a reduction in the extent of area with late contrast MR enhancement. Eur Radiol 2006;16:827836

18. Zeng L, Hu Q, Wang X, et al. Bioenergetic and functional consequences of bone marrow-derived multipotent progenitor cell transplantation in hearts with postinfarction left ventricular remodeling. Circulation 2007;115:1866-1875.

19. Saeed M, Wendland MF, Sakuma H, et al. Coronary artery stenosis: detection with contrast-enhanced MR imaging in dogs. Radiology $1995 ; 196: 79-84$.

20. Fieno DS, Hillenbrand HB, Rehwald WG, et al. Infarct resorption, compensatory hypertrophy, and differing patterns of ventricular remodeling following myocardial infarctions of varying size. J Am Coll Cardiol 2004; 43:2124-2131.

21. Kim RJ, Wu E, Rafael A, et al. The use of contrast-enhanced magnetic resonance im- aging to identify reversible myocardial dysfunction. N Engl J Med 2000;343:14451453.

22. Saeed M, Weber O, Lee R, et al. Discrimination of myocardial acute and chronic (scar) infarctions on delayed contrast enhanced magnetic resonance imaging with intravascular magnetic resonance contrast media. J Am Coll Cardiol 2006;48:1961-1968.

23. Engblom H, Hedstrom E, Heiberg E, Wagner GS, Pahlm O, Arheden H. Size and transmural extent of first-time reperfused myocardial infarction assessed by cardiac magnetic resonance can be estimated by 12-lead electrocardiogram. Am Heart J 2005;150:920e1920e9.

24. Crottogini A, Meckert PC, Vera Janavel G, et al. Arteriogenesis induced by intramyocardial vascular endothelial growth factor 165 gene transfer in chronically ischemic pigs. Hum Gene Ther 2003;14:1307-1318.

25. Dimmeler S, Zeiher AM, Schneider MD. Unchain my heart: the scientific foundations of cardiac repair. J Clin Invest 2005;115:572583.

26. Kocher AA, Schuster MD, Szabolcs MJ, et al. Neovascularization of ischemic myocardium by human bone-marrow-derived angioblasts prevents cardiomyocyte apoptosis, reduces remodeling and improves cardiac function. Nat Med 2001;7:430-436.

27. Beltrami AP, Barlucchi L, Torella D, et al. Adult cardiac stem cells are multipotent and support myocardial regeneration. Cell 2003; 114:763-776.

28. Frangogiannis NG. Targeting the inflammatory response in healing myocardial infarcts. Curr Med Chem 2006;13:1877-1893.

29. Esakof DD, Maysky M, Losordo DW, et al. Intraoperative multiplane transesophageal echocardiography for guiding direct myocardial gene transfer of vascular endothelial growth factor in patients with refractory angina pectoris. Hum Gene Ther 1999;10: $2307-2314$

30. Funatsu T, Sawa Y, Ohtake S, et al. Therapeutic angiogenesis in the ischemic canine heart induced by myocardial injection of naked complementary DNA plasmid encoding hepatocyte growth factor. J Thorac Cardiovasc Surg 2002;124:1099-1105.

31. Losordo DW, Vale PR, Isner JM. Gene therapy for myocardial angiogenesis. Am Heart J 1999;138(2 pt 2):S132-S141.

32. Saeed M, Martin AJ, Lee RJ, et al. MR guidance of targeted injections into border and core of scarred myocardium in pigs. Radiology $2006 ; 240: 419-426$.

33. Saeed M, Saloner D, Weber O, Martin A,
Henk C, Higgins C. MRI in guiding and assessing intramyocardial therapy. Eur Radiol 2005; 15:851-863

34. Sarkar N, Ruck A, Kallner G, et al. Effects of intramyocardial injection of phVEGF-A165 as sole therapy in patients with refractory coronary artery disease: 12-month followup-angiogenic gene therapy. J Intern Med 2001;250:373-381.

35. Losordo DW, Vale PR, Symes JF, et al. Gene therapy for myocardial angiogenesis: initial clinical results with direct myocardial injection of phVEGF165 as sole therapy for myocardial ischemia. Circulation 1998;98:2800 2804.

36. Sun Y, Kiani MF, Postlethwaite AE, Weber KT. Infarct scar as living tissue. Basic Res Cardiol 2002;97:343-347.

37. Sutton MG, Sharpe N. Left ventricular re modeling after myocardial infarction: pathophysiology and therapy. Circulation 2000; 101:2981-2988.

38. Mizuno S, Matsumoto K, Li MY, Nakamura T. HGF reduces advancing lung fibrosis in mice: a potential role for MMP-dependent myofibroblast apoptosis. FASEB J 2005;19: $580-582$.

39. Azuma J, Taniyama Y, Takeya Y, et al. An giogenic and antifibrotic actions of hepato cyte growth factor improve cardiac dysfunction in porcine ischemic cardiomyopathy. Gene Ther 2006;13:1206-1213.

40. Taniyama Y, Morishita R, Nakagami H, et al Potential contribution of a novel antifibrotic factor, hepatocyte growth factor, to prevention of myocardial fibrosis by angiotensin II blockade in cardiomyopathic hamsters. Circulation 2000;102:246-252.

41. Matsumoto K, Nakamura T. Emerging multi potent aspects of hepatocyte growth factor. J Biochem 1996;119:591-600.

42. Harada M, Qin Y, Takano H, et al. G-CSF prevents cardiac remodeling after myocardial infarction by activating the Jak-Stat pathway in cardiomyocytes. Nat Med 2005: 11:305-311.

43. Wang X, Hu Q, Mansoor A, et al. Bioenergetic and functional consequences of stem cell-based VEGF delivery in pressure-overloaded swine hearts. Am J Physiol Heart Circ Physiol 2006;290:H1393-H1405.

44. de Cock CC, Visser FC, Peels KH, Kamp O, van Eenige J, Roos JP. Effects of nisoldipine on systolic and diastolic function in postinfarction patients with reduced left ventricular function: a randomized, double-blind, placebo controlled study. Eur Heart J 1991; 12:1012-1019.

45. Paetsch I, Jahnke C, Wahl A, et al. Comparison 
of dobutamine stress magnetic resonance, adenosine stress magnetic resonance, and adenosine stress magnetic resonance perfusion. Circulation 2004;110:835-842.

46. Watzinger N, Saeed M, Wendland MF, Akbari H, Lund G, Higgins CB. Myocardial viability: magnetic resonance assessment of functional reserve and tissue characterization. J Cardiovasc Magn Reson 2001;3:195208.

47. Chalil S, Stegemann B, Muhyaldeen S, et al. Intraventricular dyssynchrony predicts mortality and morbidity after cardiac resynchronization therapy: a study using cardiovascu- lar magnetic resonance tissue synchronization imaging. J Am Coll Cardiol 2007;50: 243-252.

48. Schalla S, Higgins CB, Chujo M, Saeed M. Effect of potassium-channel opener therapy on reperfused infarction in hypertrophied hearts: demonstration of preconditioning by using functional and contrast-enhanced magnetic resonance imaging. J Cardiovasc Pharmacol Ther 2004;9:193-202.

49. Seghatol FF, Shah DJ, Diluzio S, et al. Relation between contractile reserve and improvement in left ventricular function with beta-blocker therapy in patients with heart failure secondary to ischemic or idiopathic dilated cardiomyopathy. Am J Cardiol 2004; 93:854-859.

50. White HD, Norris RM, Brown MA, Brandt PW, Whitlock RM, Wild CJ. Left ventricular end-systolic volume as the major determinant of survival after recovery from myocardial infarction. Circulation 1987;76:44-51.

51. Katz AM. Proliferative signaling and disease progression in heart failure. Circ J 2002;66: 225-231.

52. Pfeffer MA. Left ventricular remodeling after acute myocardial infarction. Annu Rev Med 1995;46:455-466. 


\section{Radiology 2008}

\section{This is your reprint order form or pro forma invoice}

(Please keep a copy of this document for your records.)

Reprint order forms and purchase orders or prepayments must be received 72 hours after receipt of form either by mail or by fax at 410-820-9765. It is the policy of Cadmus Reprints to issue one invoice per order.

Please print clearly.

Author Name

Title of Article

Issue of Journal

Number of Pages

Color in Article?

Reprint \#

$\mathrm{KB} \#$

Publication Date

Symbol Radiology

Please include the journal name and reprint number or manuscript number on your purchase order or other correspondence.

Order and Shipping Information

Reprint Costs (Please see page 2 of 2 for reprint costs/fees.)

Number of reprints ordered $\$$

Number of color reprints ordered \$

Number of covers ordered

Subtotal $\$$

Taxes

$\$$

(Add appropriate sales tax for Virginia, Maryland, Pennsylvania, and the District of Columbia or Canadian GST to the reprints if your order is to be shipped to these locations.)

First address included, add \$32 for each additional shipping address

TOTAL \$
Shipping Address (cannot ship to a P.O. Box) Please Print Clearly

Name

Institution

Street

City _ State __ Zip

Country

Quantity Fax

Phone: Day

E-mail Address Evening

Additional Shipping Address* (cannot ship to a P.O. Box)

Name

Institution

Street

City

Country

Quantity

Phone: Day

E-mail Address

* Add \$32 for each additional shipping address

\section{Payment and Credit Card Details}

Enclosed: Personal Check Credit Card Payment Details

Checks must be paid in U.S. dollars and drawn on a U.S. Bank.

Credit Card: _ VISA _ Am. Exp. _ MasterCard

Card Number

Expiration Date

Signature:

Please send your order form and prepayment made payable to:

\section{Cadmus Reprints}

P.O. Box 751903

Charlotte, NC 28275-1903

Note: Do not send express packages to this location, PO Box. FEIN \#:541274108

Signature

described in this document.

\section{Invoice or Credit Card Information}

Invoice Address Please Print Clearly

Please complete Invoice address as it appears on credit card statement

Name

Institution

Department

Street

City

Country

State

Phone

E-mail Address

Cadmus will process credit cards and Cadmus Journal Services will appear on the credit card statement.

If you don't mail your order form, you may fax it to 410-820-9765 with your credit card information.

Date 


\section{Radiology 2008}

Black and White Reprint Prices

Domestic (USA only)

\begin{tabular}{|c|c|c|c|c|c|c|}
\hline $\begin{array}{c}\text { \# of } \\
\text { Pages }\end{array}$ & $\mathbf{5 0}$ & $\mathbf{1 0 0}$ & $\mathbf{2 0 0}$ & $\mathbf{3 0 0}$ & $\mathbf{4 0 0}$ & $\mathbf{5 0 0}$ \\
\hline $\mathbf{1 - 4}$ & $\$ 221$ & $\$ 233$ & $\$ 268$ & $\$ 285$ & $\$ 303$ & $\$ 323$ \\
\hline $\mathbf{5 - 8}$ & $\$ 355$ & $\$ 382$ & $\$ 432$ & $\$ 466$ & $\$ 510$ & $\$ 544$ \\
\hline $\mathbf{9 - 1 2}$ & $\$ 466$ & $\$ 513$ & $\$ 595$ & $\$ 652$ & $\$ 714$ & $\$ 775$ \\
\hline $\mathbf{1 3 - 1 6}$ & $\$ 576$ & $\$ 640$ & $\$ 749$ & $\$ 830$ & $\$ 912$ & $\$ 995$ \\
\hline $\mathbf{1 7 - 2 0}$ & $\$ 694$ & $\$ 775$ & $\$ 906$ & $\$ 1,017$ & $\$ 1,117$ & $\$ 1,220$ \\
\hline $\mathbf{2 1 - 2 4}$ & $\$ 809$ & $\$ 906$ & $\$ 1,071$ & $\$ 1,200$ & $\$ 1,321$ & $\$ 1,471$ \\
\hline $\mathbf{2 5 - 2 8}$ & $\$ 928$ & $\$ 1,041$ & $\$ 1,242$ & $\$ 1,390$ & $\$ 1,544$ & $\$ 1,688$ \\
\hline $\mathbf{2 9 - 3 2}$ & $\$ 1,042$ & $\$ 1,178$ & $\$ 1,403$ & $\$ 1,568$ & $\$ 1,751$ & $\$ 1,924$ \\
\hline Covers & $\$ 97$ & $\$ 118$ & $\$ 215$ & $\$ 323$ & $\$ 442$ & $\$ 555$ \\
\hline
\end{tabular}

\begin{tabular}{|c|c|c|c|c|c|c|}
\hline \multicolumn{7}{|c|}{ International (includes Canada and Mexico) } \\
\hline $\begin{array}{c}\text { \# of } \\
\text { Pages }\end{array}$ & $\mathbf{5 0}$ & $\mathbf{1 0 0}$ & $\mathbf{2 0 0}$ & $\mathbf{3 0 0}$ & $\mathbf{4 0 0}$ & $\mathbf{5 0 0}$ \\
\hline $\mathbf{1 - 4}$ & $\$ 272$ & $\$ 283$ & $\$ 340$ & $\$ 397$ & $\$ 446$ & $\$ 506$ \\
\hline $\mathbf{5 - 8}$ & $\$ 428$ & $\$ 455$ & $\$ 576$ & $\$ 675$ & $\$ 784$ & $\$ 884$ \\
\hline $\mathbf{9 - 1 2}$ & $\$ 580$ & $\$ 626$ & $\$ 805$ & $\$ 964$ & $\$ 1,115$ & $\$ 1,278$ \\
\hline $\mathbf{1 3 - 1 6}$ & $\$ 724$ & $\$ 786$ & $\$ 1,023$ & $\$ 1,232$ & $\$ 1,445$ & $\$ 1,652$ \\
\hline $\mathbf{1 7}-\mathbf{2 0}$ & $\$ 878$ & $\$ 958$ & $\$ 1,246$ & $\$ 1,520$ & $\$ 1,774$ & $\$ 2,030$ \\
\hline $\mathbf{2 1 - 2 4}$ & $\$ 1,022$ & $\$ 1,119$ & $\$ 1,474$ & $\$ 1,795$ & $\$ 2,108$ & $\$ 2,426$ \\
\hline $\mathbf{2 5 - 2 8}$ & $\$ 1,176$ & $\$ 1,291$ & $\$ 1,700$ & $\$ 2,070$ & $\$ 2,450$ & $\$ 2,813$ \\
\hline $\mathbf{2 9 - 3 2}$ & $\$ 1,316$ & $\$ 1,452$ & $\$ 1,936$ & $\$ 2,355$ & $\$ 2,784$ & $\$ 3,209$ \\
\hline Covers & $\$ 156$ & $\$ 176$ & $\$ 335$ & $\$ 525$ & $\$ 716$ & $\$ 905$ \\
\hline
\end{tabular}

Minimum order is 50 copies. For orders larger than 500 copies, please consult Cadmus Reprints at 800-407-9190.

\section{Reprint Cover}

Cover prices are listed above. The cover will include the publication title, article title, and author name in black.

\section{Shipping}

Shipping costs are included in the reprint prices. Domestic orders are shipped via UPS Ground service. Foreign orders are shipped via a proof of delivery air service.

\section{Multiple Shipments}

Orders can be shipped to more than one location. Please be aware that it will cost $\$ 32$ for each additional location.

\section{Delivery}

Your order will be shipped within 2 weeks of the journal print date. Allow extra time for delivery.

\section{Color Reprint Prices}

\begin{tabular}{|c|c|c|c|c|c|c|}
\hline \multicolumn{7}{|c|}{ Domestic (USA only) } \\
\hline $\begin{array}{c}\text { \# of } \\
\text { Pages }\end{array}$ & $\mathbf{5 0}$ & $\mathbf{1 0 0}$ & $\mathbf{2 0 0}$ & $\mathbf{3 0 0}$ & $\mathbf{4 0 0}$ & $\mathbf{5 0 0}$ \\
\hline $\mathbf{1 - 4}$ & $\$ 223$ & $\$ 239$ & $\$ 352$ & $\$ 473$ & $\$ 597$ & $\$ 719$ \\
\hline $\mathbf{5 - 8}$ & $\$ 349$ & $\$ 401$ & $\$ 601$ & $\$ 849$ & $\$ 1,099$ & $\$ 1,349$ \\
\hline $\mathbf{9 - 1 2}$ & $\$ 486$ & $\$ 517$ & $\$ 852$ & $\$ 1,232$ & $\$ 1,609$ & $\$ 1,992$ \\
\hline $\mathbf{1 3 - 1 6}$ & $\$ 615$ & $\$ 651$ & $\$ 1,105$ & $\$ 1,609$ & $\$ 2,117$ & $\$ 2,624$ \\
\hline $\mathbf{1 7 - 2 0}$ & $\$ 759$ & $\$ 787$ & $\$ 1,357$ & $\$ 1,997$ & $\$ 2,626$ & $\$ 3,260$ \\
\hline $\mathbf{2 1 - 2 4}$ & $\$ 897$ & $\$ 924$ & $\$ 1,611$ & $\$ 2,376$ & $\$ 3,135$ & $\$ 3,905$ \\
\hline $\mathbf{2 5 - 2 8}$ & $\$ 1,033$ & $\$ 1,071$ & $\$ 1,873$ & $\$ 2,757$ & $\$ 3,650$ & $\$ 4,536$ \\
\hline $\mathbf{2 9 - 3 2}$ & $\$ 1,175$ & $\$ 1,208$ & $\$ 2,122$ & $\$ 3,138$ & $\$ 4,162$ & $\$ 5,180$ \\
\hline Covers & $\$ 97$ & $\$ 118$ & $\$ 215$ & $\$ 323$ & $\$ 442$ & $\$ 555$ \\
\hline
\end{tabular}

\begin{tabular}{|c|c|c|c|c|c|c|}
\hline \multicolumn{7}{|c|}{ International (includes Canada and Mexico)) } \\
\hline $\begin{array}{c}\text { \# of } \\
\text { Pages }\end{array}$ & $\mathbf{5 0}$ & $\mathbf{1 0 0}$ & $\mathbf{2 0 0}$ & $\mathbf{3 0 0}$ & $\mathbf{4 0 0}$ & $\mathbf{5 0 0}$ \\
\hline $\mathbf{1 - 4}$ & $\$ 278$ & $\$ 290$ & $\$ 424$ & $\$ 586$ & $\$ 741$ & $\$ 904$ \\
\hline $\mathbf{5 - 8}$ & $\$ 429$ & $\$ 472$ & $\$ 746$ & $\$ 1,058$ & $\$ 1,374$ & $\$ 1,690$ \\
\hline $\mathbf{9 - 1 2}$ & $\$ 604$ & $\$ 629$ & $\$ 1,061$ & $\$ 1,545$ & $\$ 2,011$ & $\$ 2,494$ \\
\hline $\mathbf{1 3 - 1 6}$ & $\$ 766$ & $\$ 797$ & $\$ 1,378$ & $\$ 2,013$ & $\$ 2,647$ & $\$ 3,280$ \\
\hline $\mathbf{1 7 - 2 0}$ & $\$ 945$ & $\$ 972$ & $\$ 1,698$ & $\$ 2,499$ & $\$ 3,282$ & $\$ 4,069$ \\
\hline $\mathbf{2 1 - 2 4}$ & $\$ 1,110$ & $\$ 1,139$ & $\$ 2,015$ & $\$ 2,970$ & $\$ 3,921$ & $\$ 4,873$ \\
\hline $\mathbf{2 5 - 2 8}$ & $\$ 1,290$ & $\$ 1,321$ & $\$ 2,333$ & $\$ 3,437$ & $\$ 4,556$ & $\$ 5,661$ \\
\hline $\mathbf{2 9 - 3 2}$ & $\$ 1,455$ & $\$ 1,482$ & $\$ 2,652$ & $\$ 3,924$ & $\$ 5,193$ & $\$ 6,462$ \\
\hline Covers & $\$ 156$ & $\$ 176$ & $\$ 335$ & $\$ 525$ & $\$ 716$ & $\$ 905$ \\
\hline
\end{tabular}

\section{Tax Due}

Residents of Virginia, Maryland, Pennsylvania, and the District of Columbia are required to add the appropriate sales tax to each reprint order. For orders shipped to Canada, please add 7\% Canadian GST unless exemption is claimed.

\section{Ordering}

Reprint order forms and purchase order or prepayment is required to process your order. Please reference journal name and reprint number or manuscript number on any correspondence. You may use the reverse side of this form as a proforma invoice. Please return your order form and prepayment to:

\section{Cadmus Reprints \\ P.O. Box 751903 \\ Charlotte, NC 28275-1903}

Note: Do not send express packages to this location, PO Box. FEIN \#:541274108

Please direct all inquiries to:

Rose A. Baynard

800-407-9190 (toll free number) 410-819-3966 (direct number) 410-820-9765 (FAX number) baynardr@cadmus.com (e-mail)
Reprint Order Forms and purchase order or prepayments must be received 72 hours after receipt of form. 